\title{
Simultaneous detection of severe acute respiratory syndrome, Middle East respiratory syndrome, and related bat coronaviruses by real-time reverse transcription PCR
}

\author{
Ji Yeong Noh ${ }^{1,2} \cdot$ Sun-Woo Yoon ${ }^{1,3} \cdot$ Doo-Jin Kim ${ }^{1}$ Moo-Seung Lee ${ }^{1,3} \cdot$ \\ Ji-Hyung Kim ${ }^{1} \cdot$ Woonsung $\mathrm{Na}^{4} \cdot$ Daesub Song $^{4} \cdot$ Dae Gwin Jeong ${ }^{1,3}$. \\ Hye Kwon Kim ${ }^{1}$
}

Received: 17 November 2016/ Accepted: 2 February 2017/Published online: 20 February 2017

(C) Springer-Verlag Wien 2017

\begin{abstract}
Since severe acute respiratory syndrome (SARS) and Middle East respiratory syndrome (MERS) coronaviruses (CoVs) share similar characteristics with respect to clinical signs, etiology, and transmission, methods for a rapid and accurate differential diagnosis are important. Therefore, the aim of this study was to develop a duplex real-time reverse transcription (RT)-PCR method for the simultaneous detection of these viruses. Primers and probes that target the conserved spike S2 region of human SARS$\mathrm{CoV}$, MERS-CoV, and their related bat $\mathrm{CoVs}$ were designed. The results of real-time RT-PCR showed specific reactions for each virus with adequate detection limits of 50-100 copies/mL and 5-100 copies/mL using pUC57SARS-pS2 (a template for SARS-CoV) and pGEM-MERSS2 (a template for MERS-CoV), respectively. In addition, this real-time RT-PCR system was able to detect the target viruses SARS-like bat $\mathrm{CoV}$ and MERS-CoV in bat fecal samples and sputum of MERS patients, respectively. Therefore, this newly developed real-time RT-PCR method is expected to detect not only SARS-CoV and MERS-CoV
\end{abstract}

Dae Gwin Jeong

dgjeong@kribb.re.kr

$\triangle$ Hye Kwon Kim

khk1329@kribb.re.kr

1 Infectious Disease Research Center, Korea Research Institute of Bioscience and Biotechnology, Daejeon, Republic of Korea

2 College of Veterinary Medicine, Chungbuk National University, Cheongju 28644, Republic of Korea

3 Bio-Analytical Science Division, Korea University of Science and Technology (UST), Daejeon, Republic of Korea

4 Department of Pharmacy, College of Pharmacy, Korea University, Sejong, Republic of Korea in humans but also several bat CoVs that are closely related to these viruses in bats.

\section{Introduction}

The recent emergence of human coronaviruses (CoVs) causing severe acute respiratory syndrome (SARS) and Middle East respiratory syndrome (MERS) with global spread represents a significant threat to public health. Both SARS-CoV and MERS-CoV cause severe respiratory diseases and belong to the genus Betacoronavirus [1]. Phylogenetic analysis has shown that SARS-CoV belongs to lineage $\mathrm{B}$, which includes SARS-like bat $\mathrm{CoVs}$ and some other bat-derived $\mathrm{CoVs}$, whereas MERS-CoV belongs to lineage $\mathrm{C}$, which also includes bat-derived CoVs [1].

SARS-CoV and MERS-CoV share similar transmission characteristics. Both viruses are thought to have originated from bats, which are the primary reservoir of diverse CoVs [2]. Cross-species transmission of these viruses to palm civets and dromedary camels has increased the chance of their zoonotic transmission to humans [3]. Nosocomial transmission is thought to be the main cause of human-tohuman transmission of SARS-CoV and MERS-CoV [4].

Although there have been no SARS cases reported since 2004, MERS cases have been reported continuously worldwide [3]. In addition, a recent analysis of the SARSlike bat CoVs that use the ACE2 receptor highlighted the need for preparedness for their potential zoonotic transmission [5, 6]. Bat CoVs related to SARS-CoV and MERS$\mathrm{CoV}$ have been reported continuously worldwide [7-10].

Given the high similarity between SARS-CoV and MERS-CoV with respect to clinical signs, etiology, and transmission, establishment of a simultaneous detection method for these viruses would be useful for their accurate 
diagnosis and monitoring in humans as well as their reservoir, bats. Therefore, in this study, a duplex real-time reverse transcription (RT)-PCR method was developed based on primers and probes that target the conserved spike S2 region of SARS-CoV, SARS-like bat CoVs, MERS$\mathrm{CoV}$, and MERS-related bat CoVs.

\section{Materials and methods}

\section{Primers and probes}

For the universal detection of SARS-CoV and SARS-like bat $\mathrm{CoVs}$, consensus primers and probes (Fig. 1a) were designed based on the conserved sequences of the spike S2 region by aligning the following reference sequences: human SARS-CoVs Sino1 (GenBank no. AY485277), Tor2 (AY274119), and Urbani (AY278741); SARS-like bat CoVs B15-21 (KU528591), RP3 (DQ071615), RsSHC014 (KC881005), Rf1 (DQ412042), HKU3 (DQ084199), and 273 (DQ648856).

For the detection of MERS-CoV and possible related bat CoVs, consensus primers and probes (Fig. 1b) were designed based on the conserved sequences of the spike S2 region by aligning the following reference sequences: human MERS-CoVs THA-CU (KT225476), Jeddah (KF958702), and KOR-NIH (KT029139); MERS-related bat CoVs A434 (DQ648790), PML-PHE1 (KC869678), GX2012 (KJ473822), HKU5 (EF065512), SC2013 (KJ473821), and HKU4 (EF065508). The designed primers and probes are shown in Table 1.

\section{Preparation of standard plasmids}

The partial sequences of the S2 region (nucleotides 3221-3620) of the spike gene of the SARS-CoV Sino1 strain (GenBank no. AY485277), including the primer- and probe-binding regions, were synthesized and inserted in the
pUC57 vector at CosmoGenetech Co., Ltd. (Seoul, Korea). The nucleotide sequence of the MERS-CoV S2 domain (amino acids 765-1288, EMC strain, GenBank no. JX869059) was cloned in the pGEM vector by Bioneer (Daejeon, Korea). Competent Escherichia coli cells (DH5 $\alpha$ ) were transformed with the recombinant plasmid vectors (pUC57-SARS-pS2 and pGEM-MERS-S2), and the amplified plasmid was extracted. These plasmids were then used as templates for the positive control as well as in the detection limit test after calculating their copy numbers.

\section{In vitro transcription}

A portion of the S2 region of pUC57-SARS-pS2 was amplified using primers containing a $\mathrm{T} 7$ promoter sequence: SARS-Tem-F (5'-tcg gta ccT AAT ACG ACT CAC TAT AGG Gaa gaG CCA CCA TGA AGG TGT TTT TGT GTT TAA TGG-3') and SARS-Tem-R (5'-TTT TTT TTT TTT TTT TTT TTT TTT TTT TTT tta ATT AGT CCA GCA ATG AAG CC-3'). The amplified PCR product was used as template for in vitro transcription using an mMESSAGE mMACHINE T7 kit (Ambion, USA) following the manufacturer's manual. The in vitrotranscribed mRNA was treated with Turbo DNase (2 U/ $\mu \mathrm{L})$ and purified with lithium chloride precipitation solution (7.5 M lithium chloride, $50 \mathrm{mM}$ EDTA). The final concentration of SARS-pS2-based mRNA was measured using a NanoDrop 2000 spectrophotometer (Thermo Scientific, USA).

\section{Real-time RT-PCR}

A SensifAST Probe No-ROX One-Step Kit (BIOLINE, Taunton, MA, USA) was used for the real-time RT-PCRs. Each $20-\mu \mathrm{L}$ reaction consisted of $4 \mu \mathrm{L}$ of template, $0.8 \mu \mathrm{L}$ of each primer (SCOV-F/R and MCOV-F/R, $10 \mu \mathrm{M}$ each), $10 \mu \mathrm{L}$ of $2 \mathrm{X}$ SensiFAST Probe No-ROX One-Step Mix, $0.2 \mu \mathrm{L}$ of each probe (SCOV-probe and MCOV-probe,

\section{(A)}
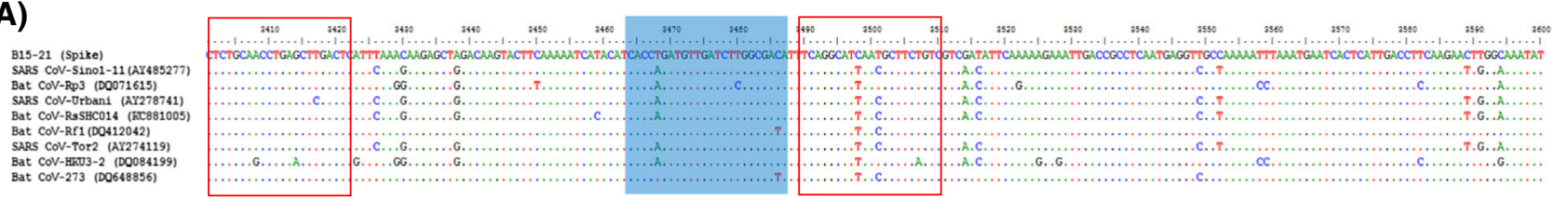

(B)
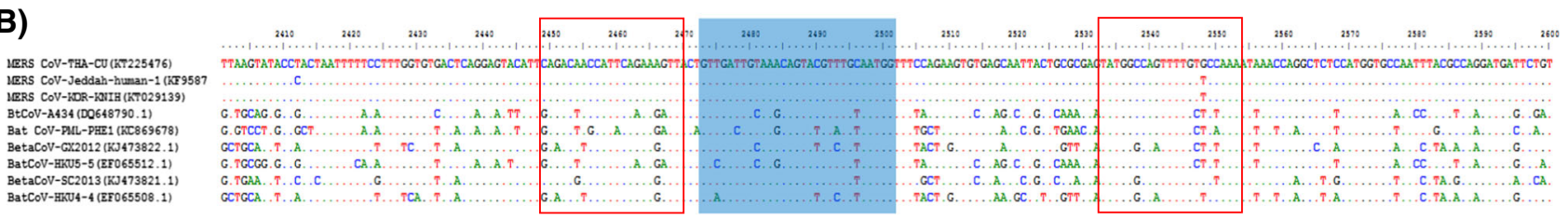

Fig. 1 Multiple sequence alignment of the spike S2 region of SARS-CoV and SARS-like bat CoVs (a) and MERS-CoV and MERS-like bat CoVs (b). Primer-binding sites are indicated by unshaded boxes, and probe-binding sites are indicated by shaded boxes 
Table 1 Primers and probes

\begin{tabular}{llll}
\hline Target & $\begin{array}{l}\text { Oligo } \\
\text { name }\end{array}$ & Sequence & $\begin{array}{l}\text { Amplicon } \\
\text { size }\end{array}$ \\
\hline Spike S2 region of SARS-CoVs and SARS-like bat & SCOV-F & $5^{\prime}$-TCT GCA ACC TGA GCT TGA CT-3' & 105 bp \\
CoVs & SCOV-R & $5^{\prime}$-ACA GAA GCR TTA ATG CCT GA-3' \\
& SCOV- & $5^{\prime}$ 6-FAM-CAC CWG ATG TTG ATC TTG GCG ACA-3' \\
& Probe & BHQ-1 & \\
Spike S2 region of MERS-CoVs and MERS- & MCOV-F & $5^{\prime}$-CAG ACA ACC ATT CAG AAR GTT A-3' \\
related bat CoVs & MCOV-R & $5^{\prime}$-TTT AGA ACA AAA CTG GCC ATA-3' \\
& MCOV- & $5^{\prime}$ 6-HEX-GTT GAT TGT AAA CAG TAC GTT TGC AAT \\
& Probe & GG-3' BHQ-1 & \\
\hline
\end{tabular}

$10 \mu \mathrm{M}$ each), $0.2 \mu \mathrm{L}$ of reverse transcriptase, $0.4 \mu \mathrm{L}$ of RiboSafe RNase Inhibitor, and $1.8 \mu \mathrm{L}$ of distilled water. The real-time RT-PCR was performed with reverse transcription at $45{ }^{\circ} \mathrm{C}$ for $10 \mathrm{~min}$ followed by $95^{\circ} \mathrm{C}$ for $2 \mathrm{~min}$ and cycling 35 times at $95{ }^{\circ} \mathrm{C}$ for $10 \mathrm{~s}$ and $60{ }^{\circ} \mathrm{C}$ for $20 \mathrm{~s}$. Thermocycling was performed using a LightCycler 96 System (Roche, USA), and positive results were estimated according to analysis of the fluorescent curves originating from each probe within 40 cycles.

\section{Estimation of the detection limits of the real-time RT-PCR}

The purified recombinant plasmids were prepared at a concentration of $1 \times 10^{8}$ copies $/ \mathrm{mL}$ for the templates of SARS-CoV and MERS-CoV. Each template was diluted tenfold in nuclease-free distilled water (Ambion, USA). The diluted plasmids were then used as templates for the real-time RT-PCR to evaluate the detection limits of the primers and probes. The in vitro-transcribed mRNA of SARS-CoV pS2 and RNA extracted from MERS-CoV isolate (KOR/KNIH/002_05_2015) were prepared at a concentration of $1 \times 10^{4} \mathrm{pg} / \mu \mathrm{L}$. They were then diluted tenfold with nuclease-free distilled water and used as template for the real-time RT-PCR to evaluate the detection limits of the primers and probes.

\section{Specificity test}

To evaluate the specificity of the primers and probes, several RNA viruses, including dengue virus types 2, 3, and 4 (KBPV-VR-29, -30, and -31, respectively; Korea Bank for Pathogenic Viruses, Seoul, Korea), porcine reproductive and respiratory syndrome virus (PRRSV) strain CP401-9, porcine epidemic diarrhea virus (PEDV) strain DR13 (Green Cross Veterinary Products, Yongin, Korea), and influenza A virus (H1N1) strain sk14 from our laboratory, were tested using the newly developed realtime RT-PCR protocol. In addition, RNA extracted from a MERS-CoV isolate (KOR/KNIH/002_05_2015), which was kindly provided by the Korea Center for Disease Control, was tested using the real-time RT-PCR system. A recombinant plasmid including partial sequences of the S2 region (nucleotides 2231-2630 of the spike gene, MERSlike bat CoV strain HKU4 [GenBank no. EF065508]) was synthesized (pUC57-MERS-like-CoV-pS2) and used as a template for the real-time RT-PCR. Agarose gel electrophoresis was performed to observe the target bands as well as for fluorescent detection.

\section{Bat samples}

RNA was extracted from 47 bat samples (feces, urine, and oral swabs) collected between July 2015 and April 2016 in Korea. Among them, samples B15-8, B15-40, B15-41, B16-6, and B16-40, and B15-21 were determined to be positive for CoVs according to consensus primers-based RT-PCR, which can detect diverse CoVs by targeting conserved sequences of the RNA-dependent RNA polymerase gene [11]. The positive samples were found to have RNA sequences that are closely related to those of alphacoronaviruses or SARS-like bat CoV [7]. Real-time PCR was performed with the extracted RNAs and compared to the previous RT-PCR results.

\section{Human samples}

MERS-CoV-positive RNA samples extracted from the sputum of MERS-CoV-infected patients were kindly provided by the Department of Laboratory Medicine of Seoul National University Hospital, Korea. According to the regulations of Category B UN 3373, the samples were packaged with triple-packaging shells following the P620 UN packaging guideline and transported to the animal biosafety-level 3 facility of the National Primate Research Center of the Korea Research Institute of Bioscience and Biotechnology by the Green Cross Labcell company, a specialist in the transport of clinical samples. The single (MERS-CoV-specific primers and probe only) and duplex real-time RT-PCR were performed with these RNAs and 
compared with the results of UpE-based real-time RT-PCR as a reference [12].

\section{Results}

\section{Detection limits of the real-time RT-PCR}

The tenfold-diluted plasmids (pUC57-SARS-pS2 and pGEM-MERS-S2) were tested by real-time RT-PCR as a single template or as mixed templates. The intensity of the fluorescence (FAM and HEX) emitted from the hydrolyzed probes was measured every cycle. Based on the measured amplification curve, the results were expressed as the quantification cycle value $(\mathrm{Cq}$ value). The $\mathrm{Cq}$ values obtained from the diluted plasmids were found to be significantly correlated with the copy numbers of each plasmid, with an $\mathrm{R}^{2}$ value of 0.9847 and 0.9954 for pUC57SARS-pS2 and pGEM-MERS-S2, respectively (Fig. 2). The negative control (distilled water) did not yield an amplification curve. As shown in Table 2, the detection limits of the real-time RT-PCR for pUC57-SARS-pS2 and pGEM-MERS-S2 were both $1 \times 10^{2}$ copies $/ \mathrm{mL}$ in the single-template condition and were $5 \times 10^{1}$ and $5 \times 10^{0}$ copies $/ \mathrm{mL}$, respectively, in the mixed-template condition. The detection limits of the real-time RT-PCR for the in vitro-transcribed mRNA of pUC57-SARS-pS2 and viral RNA of MERS CoV (KOR/KNIH/002_05_2015) were $1 \times 10^{-3}$ and $1 \times 10^{0} \mathrm{ng} / \mathrm{mL}$, respectively, in the single-template condition and were $5 \times 10^{-3}$ and $5 \times 10^{1}$
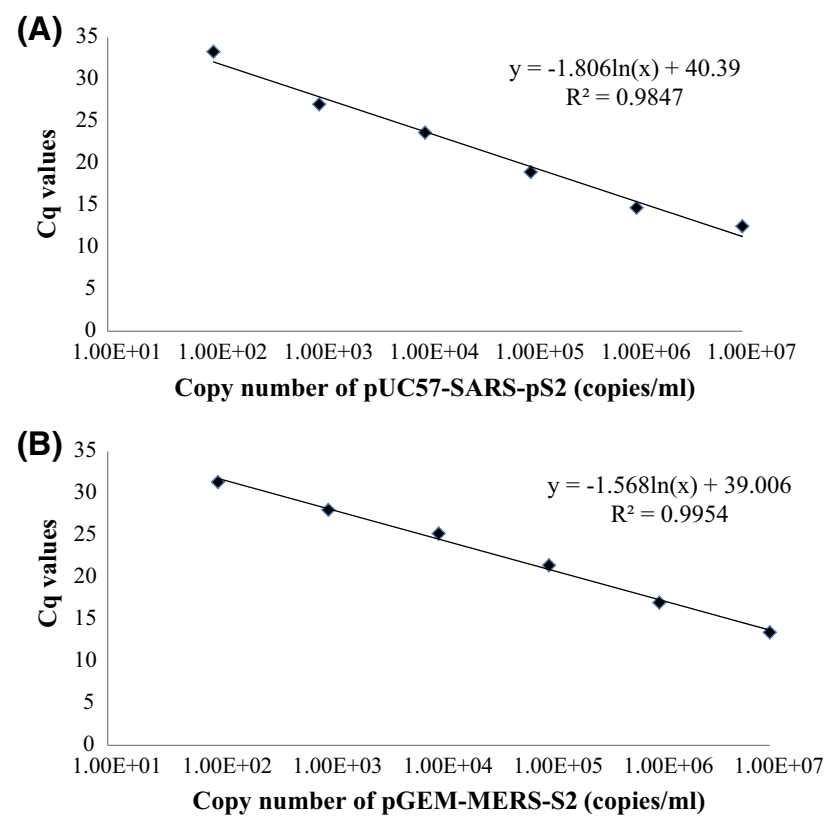

Fig. 2 Correlation curve for plasmids copy number vs. and Cq value. (a) pUC57-SARS-pS2, (b) pGEM-MERS-S2 $\mathrm{ng} / \mathrm{mL}$, respectively, in the mixed-template condition (Table 2).

\section{Specificity of the real-time RT-PCR}

The specificity of the real-time RT-PCR method developed in this study was evaluated using RNAs from several RNA viruses, including MERS-CoV (KOR/KNIH/ 002_05_2015), a recombinant plasmid for the bat CoV HKU4 strain, and RNA from a bat fecal sample containing SARS-like bat CoV. The designed primers and probes were found to be specific for MERS-CoV and SARS-like bat CoV (B15-21) (Table 3). No positive reactions were found for the bat coronavirus strain HKU4, dengue virus, PRRSV, PEDV, or influenza A virus. In the case of the HKU4 strain, although the HEX fluorescence signal was not detected, a target band of primers for MERS-CoV was detected by agarose gel electrophoresis.

\section{Application by the real-time RT-PCR method from bat fecal samples}

The extracted RNAs from a total of 47 bat samples that were previously tested using consensus primer-based RTPCR [11] were re-evaluated by the real-time RT-PCR method developed in this study. As shown in Table 4, six fecal samples were positive in the consensus-primer-based RT-PCR, and these were further sequenced and analyzed using BLASTn (http://www.ncbi.nlm.nih.gov). Among the six positive samples, five were found to be closely related to alphacoronaviruses, while one sample (B15-21) was closely related to SARS-like bat $\mathrm{CoV}$ [7]. In the real-time PCR developed in this study, five of the alphacoronaviruspositive samples were negative, but only one SARS-like bat $\mathrm{CoV}$-positive sample was positive.

\section{Application of the real-time RT-PCR method for MERS patient samples}

The RNA samples from the sputum of MERS patients were tested by the newly developed real-time RT-PCR method, and the results were compared to those obtained with UpEbased real-time RT-PCR as a reference gold-standard test (Table 5). Among the 20 samples tested, 17 were found to be positive by UpE-based real-time RT-PCR. When the single set of primers and probe for MERS-CoV was used, the newly developed real-time RT-PCR results showed $100 \%$ consistency with those of the reference test. However, when mixed sets of primers and probes for SARS$\mathrm{CoV}$ and MERS-CoV were used, $85 \%$ of the results were consistent with those of the reference test. Three falsenegative samples had $\mathrm{Cq}$ values of 33.9, 33.2, and 36.46, respectively, in the reference test. 
Table 2 Detection limits of real-time RT-PCR

\begin{tabular}{llllll}
\hline Condition & \multicolumn{2}{l}{ Plasmid concentration $($ copies $/ \mathrm{mL})$} & & \multicolumn{2}{l}{ RNA concentration $(\mathrm{ng} / \mathrm{mL})$} \\
\cline { 2 - 3 } & pUC57-SARS-pS2 & pGEM-MERS-S2 & & SARS-pS2 $^{\mathrm{a}}$ & MERS-CoV $^{\mathrm{b}}$ \\
\hline Single template & $1 \times 10^{2}$ & $1 \times 10^{2}$ & & $1 \times 10^{-3}$ & $1 \times 10^{0}$ \\
Mixed template & $5 \times 10^{1}$ & $5 \times 10^{0}$ & & $5 \times 10^{-3}$ & $5 \times 10^{1}$ \\
\hline
\end{tabular}

a mRNA obtained by in vitro transcription

b RNA from MERS-CoV isolate KOR/KNIH/002_05_2015

Table 3 Specificity of the real-time RT-PCR with various templates

\begin{tabular}{|c|c|c|c|c|c|}
\hline \multirow[t]{2}{*}{ Virus } & \multirow[t]{2}{*}{ Virus family } & \multirow[t]{2}{*}{ Template type } & \multirow{2}{*}{$\begin{array}{l}\text { Agarose gel } \\
\text { electrophoresis }\end{array}$} & \multicolumn{2}{|l|}{$\mathrm{Cq}$} \\
\hline & & & & FAM & HEX \\
\hline Dengue virus 2 (KBPV-VR-29) & Flaviviridae & RNA & - & - & - \\
\hline Dengue virus 3 (KBPV-VR-30) & Flaviviridae & RNA & - & - & - \\
\hline Dengue virus 4 (KBPV-VR-31) & Flaviviridae & RNA & - & - & - \\
\hline PRRSV (CP401-9) & Arteriviridae & RNA & - & - & - \\
\hline PEDV (DR13) & Coronaviridae & RNA & - & - & - \\
\hline Influenza A virus (sk14) & Orthomyxoviridae & RNA & - & - & - \\
\hline MERS-CoV (KOR/KNIH/002_05_2015) & Coronaviridae & RNA & + & - & 15.64 \\
\hline MERS-like bat CoV (HKU4) & Coronaviridae & Plasmid & + & - & - \\
\hline SARS-like bat CoV (B15-21) & Coronaviridae & RNA & + & 12.55 & - \\
\hline
\end{tabular}

Table 4 Real-time RT-PCR results from bat samples

\begin{tabular}{lllll}
\hline & & Positive $^{a}$ & \multicolumn{2}{c}{ Negative } \\
\cline { 3 - 5 } & & Alphacoronavirus & SARS-like CoV & \\
\hline Real-time RT-PCR & Positive & 0 & 1 & 0 \\
& Negative & 5 & 0 & 41 \\
\hline
\end{tabular}

$\bar{a}$ Samples that were positive in the RT-PCR (11) were sequenced and analyzed using BLASTn (http:// www.ncbi.nlm.nih.gov)

\section{Discussion}

The aim of this study was to develop a duplex real-time RT-PCR method for the simultaneous detection of SARS$\mathrm{CoV}$ and MERS-CoV, which are recently emerged pathogens infecting humans. As these viruses are also closely related to several bat CoVs (SARS-like bat CoVs and MERS-related bat CoVs), the primers and probes were designed based on the conserved region of the spike S2 domains of SARS-CoV, MERS-CoV, and their related bat CoVs. In a previous study, two regions within the spike protein of SARS-CoV were identified that showed a high degree of sequence conservation with those of other CoVs [13]. By applying our new approach, we expected to detect not only SARS-CoV and MERS-CoV in humans but also several bat CoVs that are closely related to these viruses.

Indeed, the newly developed real-time RT-PCR method could detect SARS-CoV- and MERS-CoV-specific sequences when the plasmids pUC57-SARS-pS2 and pGEM-MERS-S2 were used as templates. In addition, positive results were obtained when RNA extracted from MERS-CoV (KOR/KNIH/002_05_2015), which was isolated from a patient in Korea in 2015 [14], was used as a template.

The new real-time RT-PCR method also showed positive results for RNA extracted from a fecal sample containing SARS-like bat CoV (B15-21) [7]. In addition, no nonspecific amplification was found when using RNAs obtained from several RNA viruses belonging to the families Flaviviridae, Arteriviridae, and Orthomyxoviridae, and the genus Alphacoronavirus. The specific binding of the primers and probes used in the real-time RT-PCR was evaluated to determine their detection limits using serially diluted plasmids (pUC57-SARS-pS2 and pGEM-MERSS2). The detection limits of the real time RT-PCR were $50-100$ copies $/ \mathrm{mL}$ and $5-100$ copies $/ \mathrm{mL}$ for pUC57SARS-pS2 and pGEM-MERS-S2, respectively. As the previous real-time RT-PCRs were able to detect as few as 1000 copies $/ \mathrm{mL}$ and 291 copies/mL for SARS-CoV and their related bat $\mathrm{CoVs}$ and MERS-CoV, respectively 
Table 5 Results of duplex realtime RT-PCR with RNA extracted from MERS patients

\begin{tabular}{llll}
\hline Sample no. & $\begin{array}{l}\text { UpE-based } \\
\text { real-time } \\
\text { RT-PCR }\end{array}$ & $\begin{array}{l}\text { Real-time RT-PCR with } \\
\text { single primers and probe } \\
\text { set for MERS-CoV }\end{array}$ & $\begin{array}{l}\text { Real-time RT-PCR with mixed } \\
\text { primers and probe sets for } \\
\text { SARS-CoV and MERS-CoV }\end{array}$ \\
\hline 1 & $33.9^{\mathrm{a}}$ & 35.1 & - \\
2 & 32.39 & 33.28 & 31.04 \\
3 & 30.27 & 30.88 & 30.01 \\
4 & $-\mathrm{b}$ & - & - \\
5 & 31.64 & 31.4 & 29.23 \\
6 & 30.39 & 30.52 & 29.48 \\
7 & - & - & - \\
8 & 34.63 & 35.24 & 33.67 \\
9 & - & - & - \\
10 & 33.2 & 34.99 & - \\
11 & 24.2 & 23.97 & 24.15 \\
12 & 29.44 & 29.36 & 29.39 \\
13 & 29.14 & 30.44 & 29.08 \\
14 & 21.2 & 21.43 & 21.74 \\
15 & 31.54 & 31.37 & 31.25 \\
16 & 36.46 & 35.63 & - \\
17 & 30.45 & 30.01 & 30.64 \\
18 & 28.9 & 29.15 & 29.83 \\
19 & 27.93 & 28.17 & 29.88 \\
20 & 33.45 & 34.51 & 35.19 \\
\hline
\end{tabular}

${ }^{a}$ Cq value with HEX dye

${ }^{b}$ No HEX signal

[12, 15], the duplex real-time RT-PCR method developed in this study can be applied with an adequate limit of detection.

When the real-time RT-PCR was applied to the bat samples, it could specifically detect a SARS-like bat CoV, and no positive reactions were obtained with the other samples, including alphacoronavirus-positive samples. The real-time RT-PCR method developed in this study could not detect the bat CoV HKU4 strain, which belongs to the same group as human MERS-CoV. Although these viruses are in the same group, the nucleotide sequences were found to be more variable than those of SARS-CoV and its related bat CoVs (Fig. 1). However, as a target band was found in the agarose gel electrophoresis of a PCR product from the HKU4 template, the negative result obtained with HKU4 in the real-time RT-PCR method developed in this study might have been due to inefficient binding of the probe.

The new real-time RT-PCR method was also tested with RNAs extracted from the sputum of MERS patients in Korea. The single set of primers and probe for MERS-CoV could detect the same positive samples detected in the reference test, showing $100 \%$ agreement. However, when the mixed sets of primers and probes for SARS-CoV and MERS-CoV were used, the agreement was reduced to $85 \%$.
Three samples that tested positive in the reference test were not detected with the newly developed method. This may be due to the low amount of viral RNA in the sputum samples and the reduced sensitivity due to the duplex approach. In addition to using a standard test for the diagnosis of MERS-CoV infection in humans, consideration of additional tests would be helpful to avoid missing true positives.

Collectively, the newly developed real-time RT-PCR method was demonstrated to be applicable for the simultaneous detection of SARS-CoV and MERS-CoV, showing an adequate detection limit and specificity. By testing the new method with bat samples as well as human samples, it could be applicable to survey SARS-CoV, MERS-CoV, and potentially their related bat $\mathrm{CoVs}$ in bats and human samples. It could successfully detect SARS-like CoV in bat samples but showed limited detection ability for the bat CoV HKU4 strain, which is related to MERS-CoV. However, according to a recent finding of EMC-like MERS$\mathrm{CoV}$, which was detected in bats of Saudi Arabia [18], we assume that the new method can be helpful for screening for MERS-CoV in bat samples.

As novel CoVs continue to emerge around the world, real-time-PCR-based detection methods have been developed by pioneering researchers [12, 15-17]. These methods 
are applicable with good limits of detection and have been validated using field samples. However, simultaneous detection of SARS-CoV, MERS-CoV, and their related bat CoVs would be particularly useful for the detection of these viruses in humans as well as in bats, which are a known reservoir of the viruses.

Therefore, the duplex real-time RT-PCR approach for the simultaneous detection of SARS-CoV and MERS-CoV developed in this study might allow more-convenient and rapid detection of these viruses in clinical samples. In addition, this new method can be used to closely monitor related bat CoVs in bat populations, which are considered to be a primary reservoir of these viruses.

Acknowledgements This work was supported by grants from the KRIBB Initiative Program (Grant No. KGM4691511) and by the BioNano Health-Guard Research Center funded by the Ministry of Science, ICT \& Future Planning (MSIP) of Korea as a Global Frontier Project (Grant No. H-GUARD 2013M3A6B2078954). This research was also supported by a grant from the Korea Health Technology R\&D Project through the Korea Health Industry Development Institute (KHIDI), funded by the Ministry of Health \& Welfare, Republic of Korea (Grant No. HI15C3036). MERS-CoV isolate (KOR/KNIH/ 002_05_2015) was kindly provided by the Korea Center for Disease Control.

\section{Compliance with ethical standards}

Conflict of interest The authors have declared that no competing interests exist.

\section{References}

1. Su S, Wong G, Shi W, Liu J, Lai ACK, Zhou J, Liu W, Bi Y, Gao GF (2016) Epidemiology, genetic recombination, and pathogenesis of coronaviruses. Trends Microbiol 24:490-502

2. Drexler JF, Corman VM, Drosten C (2014) Ecology, evolution and classification of bat coronaviruses in the aftermath of SARS. Antiviral Res 101:45-56

3. de Wit E, van Doremalen N, Falzarano D, Munster VJ (2016) SARS and MERS: recent insights into emerging coronaviruses. Nat Rev Microbiol 14:523-534

4. Chowell G, Abdirizak F, Lee S, Lee J, Jung E, Nishiura H, Viboud C (2015) Transmission characteristics of MERS and SARS in the healthcare setting: a comparative study. BMC Med $13: 1-12$

5. Ge X-Y, Li J-L, Yang X-L, Chmura AA, Zhu G, Epstein JH, Mazet JK, Hu B, Zhang W, Peng C, Zhang YJ, Luo CM, Tan B, Wang N, Zhu Y, Crameri G, Zhang SY, Wang LF, Daszak P, Shi ZL (2013) Isolation and characterization of a bat SARS-like coronavirus that uses the ACE2 receptor. Nature 503:535-538

6. Menachery VD, Yount BL Jr, Debbink K, Agnihothram S, Gralinski LE, Plante JA, Graham RL, Scobey T, Ge XY, Donaldson EF, Randell SH, Lanzavecchia A, Marasco WA, Shi ZL, Baric RS (2015) A SARS-like cluster of circulating bat coronaviruses shows potential for human emergence. Nat Med 12:1508-1513

7. Kim HK, Yoon SW, Kim DJ, Koo BS, Noh JY, Kim JH, Choi YG, Na W, Chang KT, Song D, Jeong DG (2016) Detection of severe acute respiratory syndrome-like, Middle East respiratory syndrome-like bat coronaviruses and Group $\mathrm{H}$ rotavirus in faeces of Korean bats. Transbound Emerg Dis 63:365-372

8. Ithete NL, Stoffberg S, Corman VM, Cottontail VM, Richards LR, Schoeman MC, Drosten C, Drexler JF, Preiser W (2013) Close relative of human Middle East respiratory syndrome coronavirus in bat, South Africa. Emerg Infect Dis 19:1697-1699

9. Yang L, Wu Z, Ren X, Yang F, Zhang J, He G, Dong J, Sun L, Zhu Y, Zhang S, Jin Q (2014) MERS-related betacoronavirus in Vespertilio superans bats, China. Emerg Infect Dis 20:1260-1262

10. Yang X-L, Hu B, Wang B, Wang M-N, Zhang Q, Zhang W, Wu LJ, Ge XY, Zhang YZ, Daszak P, Wang LF, Shi ZL (2016) Isolation and characterization of a novel bat coronavirus closely related to the direct progenitor of severe acute respiratory syndrome coronavirus. J Virol 90:3253-3256

11. Poon LLM, Chu DKW, Chan KH, Wong OK, Ellis TM, Leung YHC, Lau SKP, Woo PCY, Suen KY, Yuen KY, Guan Y, Peiris JSM (2005) Identification of a novel coronavirus in bats. J Virol 79:2001-2009

12. Corman VM, Eckerle I, Bleicker T, Zaki A, Landt O, EschbachBludau M, van Boheemen S, Gopal R, Ballhause M, Bestebroer TM, Muth D, Müller MA, Drexler JF, Zambon M, Osterhaus AD, Fouchier RM, Drosten C (2012) Detection of a novel human coronavirus by real-time reverse-transcription polymerase chain reaction. Euro Surveill 17(39)

13. Ingallinella P, Bianchi E, Finotto M, Cantoni G, Eckert DM, Supekar VM, Bruckmann C, Carfi A, Pessi A (2004) Structural characterization of the fusion-active complex of severe acute respiratory syndrome (SARS) coronavirus. Proc Natl Acad Sci USA 101:8709-8714

14. Kim Y-J, Cho Y-J, Kim D-W, Yang J-S, Kim H, Park S, Han YW, Yun MR, Lee HS, Kim AR, Heo DR, Kim JA, Kim SJ, Jung HD, Kim N, Yoon SH, Nam JG, Kang HJ, Cheong HM, Lee JS, Chun J, Kim SS (2015) Complete genome sequence of Middle East respiratory syndrome coronavirus $\mathrm{KOR} / \mathrm{KNIH} /$ 002_05_2015, isolated in South Korea. Genome Announc 3:e00787-15

15. Balboni A, Gallina L, Palladini A, Prosperi S, Battilani M (2012) A real-time PCR assay for bat SARS-like coronavirus detection and its application to Italian greater horseshoe bat faecal sample surveys. Sci World J 2012:989514

16. Douglas CE, Kulesh DA, Jaissle JG, Minogue TD (2015) Realtime reverse transcriptase polymerase chain reaction assays for Middle East Respiratory Syndrome. Mol Cell Probes 29:511-513

17. Hadjinicolaou AV, Farcas GA, Demetriou VL, Mazzulli T, Poutanen SM, Willey BM, Low DE, Butany J, Asa SL, Kain KC, Kostrikis LG (2011) Development of a molecular-beacon-based multi-allelic real-time RT-PCR assay for the detection of human coronavirus causing severe acute respiratory syndrome (SARS$\mathrm{CoV})$ : a general methodology for detecting rapidly mutating viruses. Arch Virol 156:671-680

18. Memish ZA, Mishra N, Olival KJ, Fagbo SF, Kapoor V, Epstein $\mathrm{JH}$, Alhakeem R, Durosinloun A, Al Asmari M, Islam A, Kapoor A, Briese T, Daszak P, Al Rabeeah AA, Lipkin WI (2013) Middle East respiratory syndrome coronavirus in bats, Saudi Arabia. Emerg Infect Dis 19:1819-1823 